\title{
REVIEW
}

\section{Clinical review: Practical recommendations on the management of perioperative heart failure in cardiac surgery}

\author{
Alexandre Mebazaa', Antonis A Pitsis², Alain Rudiger³, Wolfgang Toller', Dan Longrois5 , Sven-Erik Ricksten 6 , \\ Ilona Bobek', Stefan De Hert ${ }^{8}$, Georg Wieselthaler ${ }^{9}$, Uwe Schirmer ${ }^{10}$, Ludwig K von Segesser ${ }^{11}$, Michael Sander ${ }^{12}$, \\ Don Poldermans ${ }^{13}$, Marco Ranucci ${ }^{14}$, Peter CJ Karpati ${ }^{15}$, Patrick Wouters ${ }^{16}$, Manfred Seeberger ${ }^{17}$, Edith R Schmid ${ }^{18}$, \\ Walter Weder ${ }^{19}$ and Ferenc Follath ${ }^{20}$
}

\begin{abstract}
Acute cardiovascular dysfunction occurs perioperatively in more than $20 \%$ of cardiosurgical patients, yet current acute heart failure (HF) classification is not applicable to this period. Indicators of major perioperative risk include unstable coronary syndromes, decompensated HF, significant arrhythmias and valvular disease. Clinical risk factors include history of heart disease, compensated HF, cerebrovascular disease, presence of diabetes mellitus, renal insufficiency and high-risk surgery. EuroSCORE reliably predicts perioperative cardiovascular alteration in patients aged less than 80 years. Preoperative B-type natriuretic peptide level is an additional risk stratification factor. Aggressively preserving heart function during cardiosurgery is a major goal. Volatile anaesthetics and levosimendan seem to be promising cardioprotective agents, but large trials are still needed to assess the best cardioprotective agent(s) and optimal protocol(s). The aim of monitoring is early detection and assessment of mechanisms of perioperative cardiovascular dysfunction. Ideally, volume status should be assessed by 'dynamic' measurement of haemodynamic parameters. Assess heart function first by echocardiography, then using a pulmonary artery catheter (especially in right heart dysfunction). If volaemia and heart function are in the normal range, cardiovascular dysfunction is very likely related to vascular dysfunction. In treating myocardial dysfunction, consider the following options, either alone or in combination: low-to-moderate doses of dobutamine and epinephrine, milrinone or levosimendan. In vasoplegiainduced hypotension, use norepinephrine to maintain adequate perfusion pressure. Exclude hypovolaemia in patients under vasopressors, through repeated volume assessments. Optimal perioperative use of inotropes/ vasopressors in cardiosurgery remains controversial, and further large multinational studies are needed. Cardiosurgical perioperative classification of cardiac impairment should be based on time of occurrence (precardiotomy, failure to wean, postcardiotomy) and haemodynamic severity of the patient's condition (crash and burn, deteriorating fast, stable but inotrope dependent). In heart dysfunction with suspected coronary hypoperfusion, an intra-aortic balloon pump is highly recommended. A ventricular assist device should be considered before end organ dysfunction becomes evident. Extra-corporeal membrane oxygenation is an elegant solution as a bridge to recovery and/or decision making. This paper offers practical recommendations for management of perioperative HF in cardiosurgery based on European experts' opinion. It also emphasizes the need for large surveys and studies to assess the optimal way to manage perioperative $\mathrm{HF}$ in cardiac surgery.
\end{abstract}

\section{Introduction and epidemiology}

Group recommendations

- More than $20 \%$ of patients are expected to have acute cardiovascular dysfunction in the perioperative period of cardiac surgery

*Correspondence: alexandre.mebazaa@lrb.aphp.fr

'Department of Anaesthesia and Intensive care, INSERM UMR 942, Lariboisière Hospital, University of Paris 7 - Diderot, 2 rue Ambroise Paré, 75010 Paris, France Full list of author information is available at the end of the article
- Classification of acute heart failure by European Society of Cardiology/American College of Cardiology Foundation/American Heart Association is not applicable to the perioperative period of cardiac surgery Acute heart failure (HF) is defined as a rapid onset of symptoms secondary to abnormal cardiac function resulting in an inability to pump sufficient blood at normal end-diastolic pressures. Acute HF presents clinically as cardiogenic shock, pulmonary oedema, or left/right/biventricular congestive HF, sometimes in conjunction with high blood pressure (hypertensive HF) 
or high cardiac output (CO) [1]. Epidemiological studies have revealed the high morbidity and mortality of hospitalised acute HF patients [2-4], and the European Heart Failure Survey II (EHFS II) [5] and the EFICA study (Epidémiologie Francaise de l'Insuffisance Cardiaque Aiguë) [6] have provided insights into the epidemiology of those admitted to ICUs. Differentiating between these scenarios perioperatively might be more complex than in non-cardiosurgical settings [7-9], as typical symptoms are often missing, while measured physiologic parameters are influenced by treatment. Additionally, frequently occurring cardiac stunning - a transient, reversible, postoperative contractility impairment - may require inotropic support to prevent tissue hypoperfusion and organ dysfunction.

In a recent prospective survey, the presentation and epidemiology of acute HF were compared in a medical and a cardiosurgical ICU [10]. The clinical course varied considerably in the three specified patient subgroups (medical, elective and emergency cardiosurgical patients), with outcome mostly influenced by co-morbidities, organ dysfunction, and surgical treatment options. The distinction between cardiogenic shock and transient postoperative cardiac stunning - diagnosed in $45 \%$ of elective patients - is important as they are associated with different hospital paths and outcomes (Figure 1). Patients with only postoperative stunning can usually be rapidly weaned off inotropic support.

In another study, postcardiotomy cardiogenic shock occurred in only $2 \%$ to $6 \%$ of all adult cardiosurgical procedures, albeit associated with high mortality rates [11]. Twenty-five percent of patients undergoing elective coronary artery bypass graft (CABG) surgery require inotropic support for postoperative myocardial dysfunction [12]. Transesophageal echocardiography (TEE) shows that right ventricular (RV) dysfunction is present in about $40 \%$ of postoperative patients who develop shock [13]. Postoperative cardiovascular dysfunction may also be characterised by unexpectedly low systemic vascular resistance (SVR), that is, vasodilatory shock. These findings could help in the evaluation of therapeutic options $[14,15]$.

\section{Risk stratification}

Group recommendations

- Indicators of major clinical risk in the perioperative period are: unstable coronary syndromes, decompensated HF, significant arrhythmias and severe valvular disease

- Clinical risk factors include history of heart disease, compensated HF, cerebrovascular disease, presence of diabetes mellitus, renal insufficiency and high-risk surgery

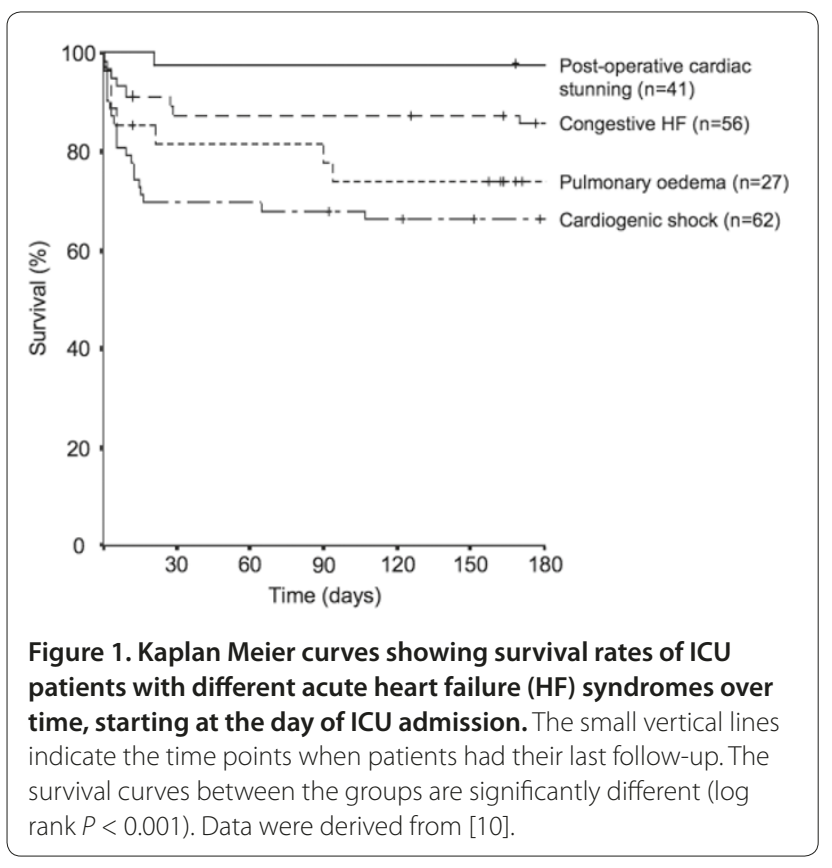

- the EuroSCORE predicts perioperative cardiovascular alteration in cardiac surgery well, although in those older than 80 years it overestimates mortality

- B-type natriuretic peptide level before surgery is an additional risk stratification factor

Risk stratification is increasingly used in open-heart surgery to help adjust available resources to predicted outcome. The latter is mostly calculated by the EuroSCORE (European System for Cardiac Operative Risk Evaluation; Table 1) [16].

As the simple EuroSCORE sometimes underestimates risk when certain combinations of risk factors co-exist, a more complete logistical version has been developed, resulting in more accurate risk prediction for particularly high risk patients. Figure 2 depicts the predicted factors of postoperative low $\mathrm{CO}$ syndrome (abscissa) versus the logit score (ordinate) for several combinations of covariate risk factors for low CO syndrome [17].

Table 2 lists other scoring systems besides the EuroSCORE used to assess risk in cardiac surgery. Essentially, according to all risk indices HF constitutes a high risk, and a left ventricular ejection fraction $\leq 35 \%$ could be an indicator of adverse outcome [18]. Compared to other risk factors, HF is especially related to poor longterm outcome. Preoperative assessment opens up a 'golden hour' for identification and initiation of therapeutic interventions in patients with myocardial viability, such as coronary revascularization, cardiac resynchronization, and medical therapy. Due to therapeutic advances, the EuroSCORE slightly overestimates the perioperative risk, which is why a project to update the sensitivity of the EuroSCORE is currently being considered [19-24]. 
Table 1. EuroSCORE: risk factors, definitions and scores [16]

\begin{tabular}{|c|c|c|}
\hline & Definition & Score \\
\hline \multicolumn{3}{|l|}{ Patient-related factors } \\
\hline Age & Per 5 years or part thereof over 60 years & 1 \\
\hline Sex & Female & 1 \\
\hline Chronic pulmonary disease & Long-term use of bronchodilators or steroids for lung disease & 1 \\
\hline Extracardiac arteriopathy & $\begin{array}{l}\text { Any one or more of the following: claudication, carotid occlusion or }>50 \% \text { stenosis, } \\
\text { previous or planned intervention on the abdominal aorta, limb arteries or carotids }\end{array}$ & 2 \\
\hline Neurological dysfunction & Disease severely affecting ambulation or day-to-day functioning & 2 \\
\hline Previous cardiac surgery & Requiring opening of the pericardium & 3 \\
\hline Serum creatinine & $>200 \mu \mathrm{mol} / \mathrm{l}$ preoperatively & 2 \\
\hline Active endocarditis & Patient still under antibiotic treatment for endocarditis at the time of surgery & 3 \\
\hline Critical preoperative state & $\begin{array}{l}\text { Any one or more of the following: ventricular tachycardia or fibrillation or aborted } \\
\text { sudden death, preoperative cardiac massage, preoperative ventilation before arrival in } \\
\text { the anaesthetic room, preoperative inotropic support, intraaortic balloon counterpulsation } \\
\text { or preoperative acute renal failure (anuria or oliguria }<10 \mathrm{ml} / \mathrm{h} \text { ) }\end{array}$ & 3 \\
\hline \multicolumn{3}{|l|}{ Cardiac-related factors } \\
\hline Unstable angina & Rest angina requiring intravenous nitrates until arrival in the anaesthetic room & 2 \\
\hline \multirow[t]{2}{*}{ LV dysfunction } & Moderate or LVEF 30 to $50 \%$ & 1 \\
\hline & Poor or LVEF $<30$ & 3 \\
\hline Recent myocardial infarct & $<90$ days & 2 \\
\hline Pulmonary hypertension & Systolic PAP >60 mmHg & 2 \\
\hline \multicolumn{3}{|l|}{ Operation-related factors } \\
\hline Emergency & Carried out on referral before the beginning of the next working day & 2 \\
\hline Other than isolated CABG & Major cardiac procedure other than or in addition to CABG & 2 \\
\hline Surgery on thoracic aorta & For disorder of ascending, arch or descending aorta & 3 \\
\hline Postinfarct septal rupture & & 4 \\
\hline
\end{tabular}

Application of scoring system: 0-2 (low risk); 3-5 (medium risk); 6 plus (high risk). CABG, coronary artery bypass graft; LV, left ventricular; LVEF, left ventricular ejection fraction; PAP, pulmonary arterial pressure.

In addition to scoring systems, levels at hospital admission of B-type natriuretic peptide (BNP) and the amino-terminal fragment of pro-BNP (NT-pro-BNP) are powerful predictors of outcome with regard to in-hospital mortality and re-hospitalization in HF patients $[25,26]$. In open-heart surgery patients, preoperative BNP levels $>385 \mathrm{pg} / \mathrm{ml}$ were an independent predictor of postoperative intra-aortic balloon pump (IABP) use, hospital length of stay, and 1-year mortality [27]. In patients undergoing aortic valve replacement, BNP levels $>312 \mathrm{pg} / \mathrm{ml}$ were an independent predictor of death [28]. Similarly, NT-pro-BNP was shown to be equivalent to the EuroSCORE and more accurate than preoperative left ventricular ejection fraction in predicting postoperative complications [29].

\section{Risk modulation: cardioprotective agents}

Group recommendations

- Aggressively preserving heart function during cardiac surgery is a major goal
- Volatile anaesthetics seem to be promising cardioprotective agents

- Levosimendan, introduced more recently, also seems to have cardioprotective properties

- Large trials are still needed to assess the best cardioprotective agent(s) and the optimal protocol to adopt

Besides cardioplegic and coronary perfusion optimisation techniques, cardioprotective agents aim to prevent or diminish the extent of perioperative ischaemiareperfusion-induced myocardial dysfunction. The mechanisms leading to myocardial injury seem to be free radical formation, calcium overload, and impairment of the coronary vasculature [30].

The ultimate goal of perioperative cardioprotective strategies is to limit the extent and consequences of myocardial ischaemia-reperfusion injury. Protective strategies include preserving and replenishing myocardial high energy phosphate stores, modulating intracellular gradients, and the use of free radical oxygen scavengers and/or antioxidants, and inhibitors of the complement 

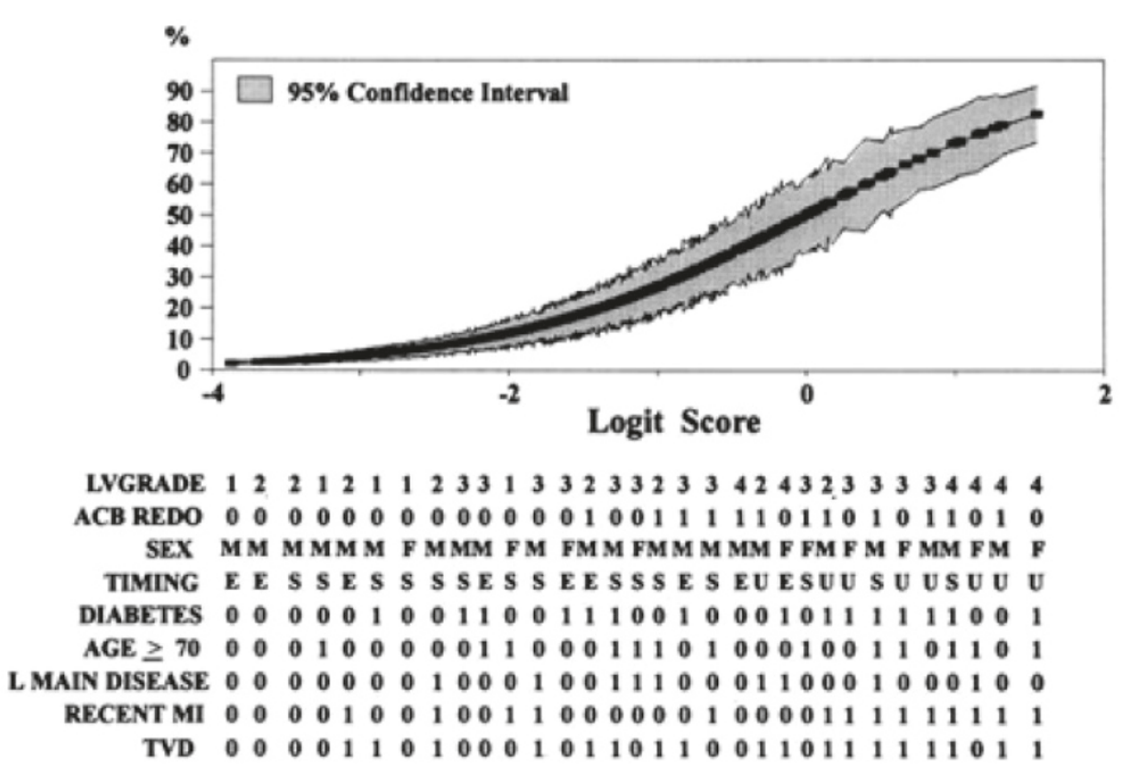

Figure 2. Predictive probability of low cardiac output syndrome after coronary artery bypass graft. Left ventricular grade (LVGRADE) SCOred from 1 to 4. Repeat aorto-coronary bypass (ACB REDO), diabetes, age older than 70 years, left main coronary artery disease (L MAIN DISEASE), recent myocardial infarction (RECENT MI), and triple-vessel disease (TVD) scored 0 for no, 1 for yes. M, male; F, female; E, elective; S, semi-elective; U, urgent. Data were derived from [17].

systems and neutrophil activation. Most of these approaches (using adenosine modulators, cardioplegia solution adjuvants, $\mathrm{Na}^{+} / \mathrm{H}^{+}$exchange inhibitors, $\mathrm{K}_{\text {ATP }}$ channel openers, anti-apoptotic agents, and many other drugs with proven or anticipated effects on the complement-inflammation pathways) have been shown to be effective in experimental and even observational clinical settings.

Clinical studies of volatile anaesthetics, which exhibit pharmacological preconditioning effects, have failed to demonstrate unequivocally beneficial effects with regard to the extent of postischaemic myocardial function and damage [31]. The use of a volatile versus intravenous anaesthetic regimen might be associated with better preserved myocardial function with less evidence of myocardial damage [32-35]. The protective effects seemed most pronounced when the volatile anaesthetic was applied throughout the entire surgical procedure [36]. Desflurane and sevoflurane have cardioprotective effects that result in decreased morbidity and mortality compared to an intravenous anaesthetic regimen [37].

Postoperative morbidity and clinical recovery remains to be established. In a retrospective study, cardiac-related mortality seemed to be lower with a volatile anaesthetic regimen, but non-cardiac death seemed to be higher in this patient population, with no difference in 30-day total mortality [38].

Levosimendan is increasingly described as a myocardial protective agent. Its anti-ischaemic effects are mediated by the opening of ATP-sensitive potassium channels [39].
Levosimendan improves cardiac performance in myocardial stunning after percutaneous intervention [40]. The latest meta-analysis, including 139 patients from 5 randomized controlled studies, showed that levosimendan reduces postoperative cardiac troponin release irrespective of cardiopulmonary bypass (CPB; Figure 3). [41] Tritapepe and colleagues [12] showed that levosimendan pre-treatment improved outcome in 106 patients undergoing CABG. A single dose of levosimendan $(24 \mu \mathrm{g} / \mathrm{kg}$ over 10 minutes $)$ administered before $\mathrm{CPB}$ reduced time to tracheal extubation, overall ICU length of stay and postoperative troponin I concentrations. In another recent study, levosimendan before $\mathrm{CPB}$ lowered the incidence of postoperative atrial fibrillation [42]. Due to the complex effects of levosimendan, and such preclinical and clinical results, the term inoprotector has been proposed to describe it [43].

\section{Monitoring}

Group recommendations

- The aim of monitoring is the early detection of perioperative cardiovascular dysfunction and assessment of the mechanism(s) leading to it

- Volume status is ideally assessed by 'dynamic' measures of haemodynamic parameters before and after volume challenge rather than single 'static' measures

- Heart function is first assessed by echocardiography followed by pulmonary arterial pressure, especially in the case of right heart dysfunction 
Table 2. Scoring systems used in cardiac surgery

\begin{tabular}{|c|c|c|c|c|}
\hline & EF with highest risk & $\begin{array}{c}\text { Incidence in } \\
\text { high-risk group* }\end{array}$ & $\begin{array}{c}\text { Mortality in } \\
\text { high-risk group }\end{array}$ & Reference \\
\hline EuroSCORE & $<30 \%$ & 3 of all, $\geq 6$ & 10.25 to $12.16 \%$ & [16] \\
\hline Pons Score & - (NYHA IV) & 10 of all, $\geq 30$ & $54.4 \%$ & {$[85]$} \\
\hline French Score & $\leq 30 \%$ & 5 of all, $>6$ & $21.2 \%$ & {$[86]$} \\
\hline Ontario Province Risk Score & $<20 \%$ & 3 of all, $\geq 8$ & $14.51 \%$ & {$[87]$} \\
\hline Cleveland Clinic Score & $<35 \%$ & 3 of all, 10 to 31 & $44.6 \%$ & [88] \\
\hline Parsonnet Score & $<30 \%$ & 4 of all, $\geq 20$ & $>20 \%$ & [89] \\
\hline
\end{tabular}

EF, ejection fraction; NYHA, New York Heart Association.

- If both volaemia and heart function are in the normal range, cardiovascular dysfunction is very likely related to vascular dysfunction

\section{Assessing optimal volume status}

Heart failure cannot be ascertained unless volume loading is optimal. The evaluation of effective circulating blood volume is more important than the total blood volume. Signs of increased sympathetic tone and/or organ hypoperfusion (increased serum lactate and decreased mixed venous saturation $\left(\mathrm{SvO}_{2}\right)$ or central venous $\mathrm{O}_{2}$ saturation $\left(\mathrm{ScvO}_{2}\right)$ ) indicate increased oxygen extraction secondary to altered cardiovascular physiology/ hypovolaemia.

It is difficult to estimate volume status using single haemodynamic measures. Pressure estimates, such as central venous pressure and pulmonary capillary wedge pressure (PCWP) - previously considered reliable measures of RV and LV preload - are generally insensitive indicators of volaemia; while low values may reflect hypovolaemia, high values do not necessarily indicate volume overload [44-47]. The uncoupling between PCWP and LV end-diastolic pressure can be the consequence of elevated pulmonary vascular resistance, pulmonary venoconstriction, mitral stenosis and reductions in transmural cardiac compliance.

Volumetric estimates of preload seem more predictive of volume status [46]. Transoesophageal echocardiography is used clinically for assessing LV end-diastolic area, while the transpulmonary thermal-dye indicator dilution technique measures intrathoracic blood volume [48], which reflects both changes in volume status and ensuing alteration in $\mathrm{CO}$, a potentially useful clinical indicator of overall cardiac preload $[49,50]$.

In predicting fluid responsiveness in ICU patients, it is preferable to use more reliable dynamic indicators reflecting hypovolaemia than static parameters [51,52]. In particular, stroke volume variation enables real-time prediction and monitoring of LV response to preload enhancement postoperatively and guides volume therapy. By contrast, central venous pressure and PCWP alterations associated with changes in circulating volumes do not correlate significantly with changes in end-diastolic volume and stroke volume. The 'gold standard' haemodynamic technique guiding volume management in critically ill patients is yet to be determined. Continuous monitoring techniques are more appropriate in assessing the perioperative volume status of HF patients.

\section{Echocardiography}

Intraoperative and postoperative transoesophageal echocardiography (TOE) and postoperative transthoracic echocardiography enable bedside visualization of the heart. Echocardiography may immediately identify causes of cardiovascular failure, including cardiac and valvular dysfunction, obstruction of the RV (pulmonary embolism) or LV outflow tract (for example, systolic anterior motion of the anterior mitral valve leaflet), or obstruction to cardiac filling in tamponade. It might differentiate between acute right, left and global HF as well as between systolic and diastolic dysfunction. Transoesophageal echocardiography influences both anaesthetists' and surgeons' therapeutic options, especially perioperatively [53].

\section{Pulmonary artery catheter (Swan-Ganz catheter)}

After almost four decades, the pulmonary artery catheter (PAC) remains a monitoring method for directly measuring circulatory blood flow in critically ill patients, including cardiosurgical patients. With regard to managing perioperative HF, the four crucial components remain measurements of heart rate, volaemia, myocardial function and vessel tone.

In RV failure, except if caused by tamponade, a PAC should be introduced after an echocardiographically established diagnosis. PACs can differentiate between pulmonary hypertension and RV ischaemia, necessitating a reduction of $R V$ afterload, as the ischaemic $R V$ is very sensitive to any afterload increase [54]. They are even more important in the worst scenario for the RV: combined increased pulmonary arterial pressure and RV ischaemia. 


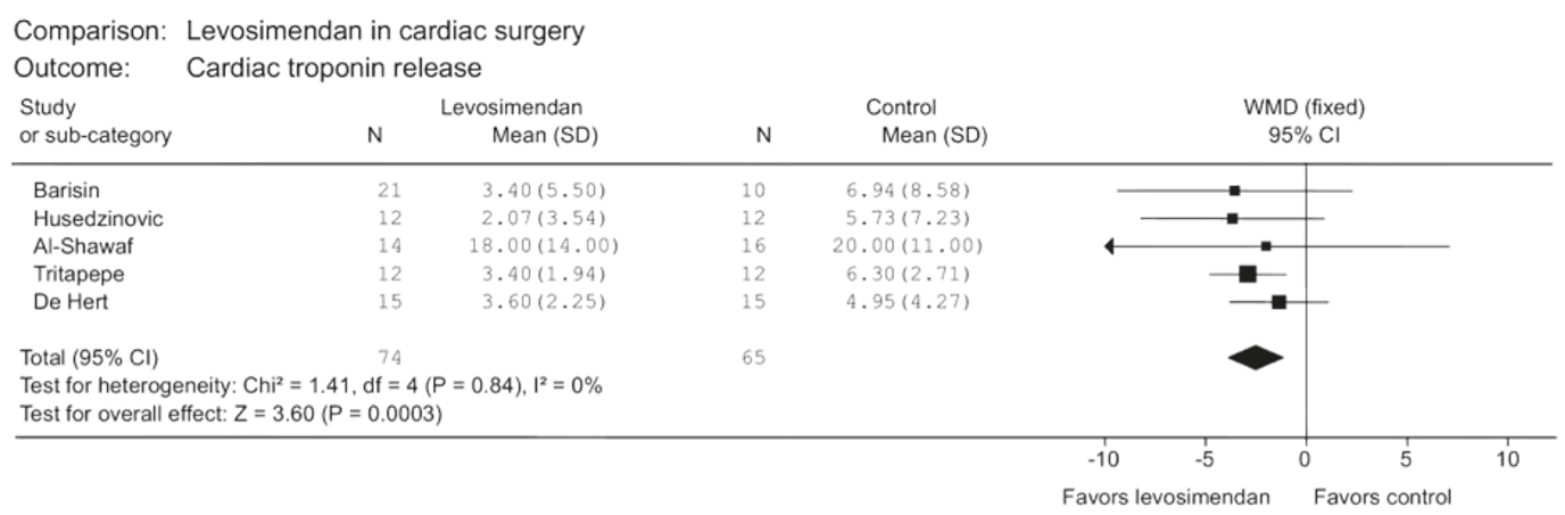

Figure 3. Cardioprotective effect of levosimendan in cardiac surgery. Figure taken from [41]. Data are from Barisin et al., Husedzinovic et al., Al-Shawaf et al. [69], Tritapepe et al. [12], and De Hert et al. [74]. Cl, confidence interval; df, degrees of freedom; SD, standard deviation; WMD, weighted mean differences.

\section{Alternative measures of stroke volume}

Recently, several devices have been designed to assess cardiac function based on pulse contour analysis of an arterial waveform (Table 3). Their value in assessing the failing heart's function is still under investigation.

\section{Pharmacological treatment of left ventricular dysfunction after cardiac surgery}

Group recommendations

- In case of myocardial dysfunction, consider the following three options either alone or combined:

- Among catecholamines, consider low-to-moderate doses of dobutamine and epinephrine: they both improve stoke volume and increase heart rate while PCWP is moderately decreased; catecholamines increase myocardial oxygen consumption

- Milrinone decreases PCWP and SVR while increasing stoke volume; milrinone causes less tachycardia than dobutamine

- Levosimendan, a calcium sensitizer, increases stoke volume and heart rate and decreases SVR

- Norepinephrine should be used in case of low blood pressure due to vasoplegia to maintain an adequate perfusion pressure. Volaemia should be repeatedly assessed to ensure that the patient is not hypovolaemic while under vasopressors

- Optimal use of inotropes or vasopressors in the perioperative period of cardiac surgery is still controversial and needs further large multinational studies

Cardiac surgery may cause acute deterioration of ventricular function during and after weaning from $\mathrm{CPB}$. Pharmacological treatment of low $\mathrm{CO}$ and reduced oxygen delivery to vital organs may be required. Inadequate treatment may lead to multiple organ failure, one of the main causes of prolonged hospital stay, postoperative morbidity and mortality and, thus, increased health care costs. However, excess inotrope usage could also be associated with deleterious effects through complex mechanisms [55].

A wide range of inotropic agents is available. Consensus regarding the pharmacological inotropic treatment for postcardiotomy heart failure and randomized controlled trials focusing on clinically important outcomes are both lacking. The vast majority of reports focus on postoperative systemic haemodynamic effects and, to some extent, on regional circulatory effects of individual inotropic agents. Furthermore, there is a shortage of comparative studies evaluating the differential systemic and regional haemodynamic effects of various inotropes on $\mathrm{CO}$ in postoperative HF. Catecholamines and phosphodiesterase inhibitors are two main groups of inotropes used for treatment of cardiac failure in heart surgery [56]. The calcium sensitizer levosimendan has recently become an interesting option for treatment of $\mathrm{HF}$ as well as in postcardiotomy ventricular dysfunction.

\section{Catecholamines}

All catecholamines have positive inotropic and chronotropic effects. In a comparison of epinephrine with dobutamine in patients recovering from CABG, they had similar effects on mean arterial pressure, central venous pressure, PCWP, SVR, pulmonary vascular resistance, and LV stroke work [57]. Furthermore, when stoke volume was increased comparably, dobutamine increased heart rate more than epinephrine. Epinephrine, dobutamine and dopamine all increase myocardial oxygen consumption $\left(\mathrm{MVO}_{2}\right)$ postoperatively [58-60]. However, only with dobutamine is this matched by a proportional increase in coronary blood flow $[58,59]$, suggesting that the other agents may impair coronary vasodilatory reserve postoperatively. Of note, commonly encountered 
Table 3. Etiology and investigation of post-cardiopulmonary bypass ventricular dysfunction

\begin{tabular}{|c|c|c|}
\hline Investigation & Finding & \\
\hline \multicolumn{3}{|l|}{ General } \\
\hline $\begin{array}{l}\text { Exacerbation of preoperative ventricular dysfunction with relative } \\
\text { intolerance to cardioplegic asystolic, hypoxic arrest }\end{array}$ & TOE & $\begin{array}{l}\text { Global or regional wall } \\
\text { motion abnormality }\end{array}$ \\
\hline Reperfusion injury & TOE & Global wall motion abnormality \\
\hline $\begin{array}{l}\text { Inadequate myocardial protection (underlying coronary anatomy, } \\
\text { route of cardioplegia, type of cardioplegia) }\end{array}$ & TOE & Global wall motion abnormality \\
\hline \multicolumn{3}{|l|}{ Case/patient specific } \\
\hline \multicolumn{3}{|l|}{ Ischaemia/infarction } \\
\hline Vessel spasm (native coronaries, internal mammary artery) & ECG, TOE, graft flow & $\begin{array}{l}\text { ECG changes, regional wall motion } \\
\text { abnormality, poor graft flow }\end{array}$ \\
\hline Emboli (air, clot, particulate matter) & ECG, TOE, graft flow & $\begin{array}{l}\text { ECG changes, regional wall motion } \\
\text { abnormality, poor graft flow }\end{array}$ \\
\hline Technical graft anastomotic tissues & ECG, TOE, graft flow & $\begin{array}{l}\text { ECG changes, regional wall motion } \\
\text { abnormality, poor graft flow }\end{array}$ \\
\hline Kink/clotting of bypass grafts, native vessels & $\begin{array}{l}\text { ECG, TOE, graft flow, } \\
\text { inspection }\end{array}$ & $\begin{array}{l}\text { ECG changes, regional wall motion } \\
\text { abnormality, poor graft flow }\end{array}$ \\
\hline \multicolumn{3}{|l|}{ Incomplete revascularization } \\
\hline \multicolumn{3}{|l|}{ Non-graftable vessels } \\
\hline \multicolumn{3}{|l|}{ Known intrinsic disease } \\
\hline \multicolumn{3}{|l|}{ Metabolic } \\
\hline Hypoxia, hypercarbia & \multicolumn{2}{|l|}{$\begin{array}{l}\text { ABG, electrolytes, } \\
\text { check ventilation }\end{array}$} \\
\hline Hypokalemia, hyperkalemia & \multicolumn{2}{|l|}{ Electrolytes } \\
\hline \multicolumn{3}{|l|}{ Uncorrected pathology } \\
\hline Hypertrophic cardiomyopathy & TOE & Abnormal outflow gradient, SAM \\
\hline Valve gradients & TOE & Abnormal valve gradient \\
\hline Shunts & TOE & Abnormal Doppler jet \\
\hline \multicolumn{3}{|l|}{ Mechanical issues } \\
\hline Prosthetic valve function & TOE & $\begin{array}{l}\text { Poor leaflet motion, abnormal } \\
\text { gradient }\end{array}$ \\
\hline Intracardiac shunt (ASD, VSD) & TOE & Abnormal Doppler jet \\
\hline \multicolumn{3}{|l|}{ Conduction issues } \\
\hline Bradycardia & ECG & Heart rate less than 60 \\
\hline Atrioventricular dissociation & ECG & Third degree heart block \\
\hline Atrial fibrillation & $\mathrm{ECG}, \mathrm{ABG}$, electrolytes & Hypoxia, electrolyte abnormality \\
\hline Ventricular arrhythmias & $E C G, A B G$, electrolytes & Hypoxia, electrolyte abnormality \\
\hline Vasodilation & $\begin{array}{l}\text { Transpulmonary thermodilation, } \\
\text { Swan-Ganz monitoring }\end{array}$ & $\begin{array}{l}\text { Decreased systemic vascular } \\
\text { resistance }\end{array}$ \\
\hline Hypovolemia & Stroke volume monitoring & $\begin{array}{l}\text { Decreased stroke volume, } \\
\text { increased SWV }\end{array}$ \\
\hline \multicolumn{3}{|l|}{ Pulmonary hypertension } \\
\hline $\begin{array}{l}\text { Pre-existing elevated pulmonary pressures, hypoxia, } \\
\text { hypercarbia, fluid overload }\end{array}$ & $A B G$ & $\begin{array}{l}\text { Elevated pulmonary artery } \\
\text { pressures, hypoxia, hypercarbia, } \\
\text { RV distention }\end{array}$ \\
\hline \multicolumn{3}{|l|}{ Right ventricular failure } \\
\hline $\begin{array}{l}\text { Elevated pulmonary pressures, inadequate myocardial } \\
\text { protection, emboli to native or bypass circulation, fluid overload }\end{array}$ & $\begin{array}{l}\text { Swan-Ganz monitoring, ABG, } \\
\text { TOE }\end{array}$ & $\begin{array}{l}\text { RV distention, poor RV wall motion, } \\
\text { elevated pulmonary artery pressure, } \\
\text { elevated central venous pressure }\end{array}$ \\
\hline
\end{tabular}


phenomena associated with epinephrine use include hyperlactateaemia and hyperglycaemia. Dopexamine has no haemodynamic advantage over dopamine or dobutamine $[61,62]$ in LV dysfunction.

\section{Phosphodiesterase III inhibitors}

Phosphodiesterase III inhibitors, such as amrinone, milrinone or enoximone, are all potent vasodilators that cause reductions in cardiac filling pressures, pulmonary vascular resistance and SVR [63-65]; they are commonly used in combination with $\beta_{1}$-adrenergic agonists. Compared to dobutamine in postoperative low $\mathrm{CO}$, phosphodiesterase III inhibitors caused a less pronounced increase in heart rate and decreased the likelihood of arrhythmias [66-68]; also, the incidence of postoperative myocardial infarction was significantly lower $(0 \%)$ with amrinone compared to dobutamine (40\%) [66]. This could be explained by phosphodiesterase III inhibitors decreasing $\mathrm{LV}$ wall tension without increasing $\mathrm{MVO}_{2}$, despite increases in heart rate and contractility, in striking contrast to catecholamines [59].

\section{Levosimendan}

Levosimendan has been recommended for the treatment of acute HF [8] and was recently used for the successful treatment of low $\mathrm{CO}$ after cardiac surgery [69-71]. The effects of levosimendan have been compared to those of dobutamine [72,73] and milrinone $[69,74]$. Levosimendan has been shown to decrease the time to extubation compared to milrinone [74]. Compared to dobutamine, levosimendan decreases the incidence of postoperative atrial fibrillation [42] and myocardial infarction, ICU length of stay [73], acute renal dysfunction, ventricular arrhythmias, and mortality in the treatment of postoperative LV dysfunction. Levosimendan showed little change in $\mathrm{MVO}_{2}$ [75] and improved early heart relaxation after aortic valve replacement. [76].

In summary, the above described inotropic agents can be started either alone or in combination with an agent from another class (multimodal approach) in myocardial depression. Common examples include norepinephrine with dobutamine or phosphodiesterase III inhibitors, and dobutamine with levosimendan. The beneficial effects of treatment with inotropic agents on outcome in the management of postoperative low $\mathrm{CO}$ need to be confirmed in a large multicentre study.

\section{Clinical scenarios}

Group recommendations

- The classification of cardiac impairment in the perioperative period of cardiac surgery should be based on the time of occurrence:

- precardiotomy
- failure to wean

- postcardiotomy

and on the haemodynamic severity of the condition of the patient:

- crash and burn

- deteriorating fast

- stable but inotrope dependent

In cardiosurgical patients the timing of surgical intervention in relationship to the development of acute HF with subsequent cardiogenic shock is of utmost importance, leading to three distinct clinical scenarios: precardiotomy HF, failure to wean and postcardiotomy HF. While their names are self-explanatory, these three distinct clinical scenarios differ from each other substantially concerning diagnosis, monitoring and management.

There is consensus that cardiogenic shock is the severest form of HF; regardless of aetiology, pathophysiology, or initial clinical presentation, it can be the final stage of both acute and chronic HF, with the highest mortality (Table 4).

\section{Precardiotomy heart failure}

In the precardiotomy HF profile the underlying pathology may still be obscure. Altered LV function primarily due to myocardial ischaemia is one of the most frequent causes of precardiotomy low output syndrome. The patient may be anywhere in the hospital or pre-hospital setting, with or without an initial working diagnosis, and quite often only basic monitoring options are available. The availability of life support measures may be limited compared with the other two scenarios. The primary aim being the patient's survival, priorities focus on deciding the steps necessary for diagnosis and treatment. The next priority should be surgery avoiding further alterations in myocardial function, possibly by introducing an IABP preoperatively. As described above, preoperative poor LV function is the most important predictor of postoperative morbidity and mortality after CABG. However, the dysfunctional myocardium may not be irreversibly damaged and possibly only 'stunned' or 'hibernating. Revascularization of the reversibly injured heart areas may result in improved LV performance. Still cold injury or inhomogeneous cardioplegic delivery may exacerbate perioperative ischaemic injury, resulting in inadequate early postoperative ventricular function [77]. Prolonged reperfusion with a terminal 'hot shot' of cardioplegic solution may restore function in patients with poor ventricular function [78]. Warm cardioplegia may improve postoperative LV function in patients with highrisk conditions [77]. Some patients will continue to have poor ventricular function postoperatively, restricting the role of myocardial protection to limiting the extent of perioperative injury [79]. 
Table 4. The three clinical heart failure scenarios and the clinical profiles in each scenario

\begin{tabular}{|c|c|}
\hline Clinical scenarios & Clinical profiles in each scenario \\
\hline \multicolumn{2}{|l|}{ Precardiotomy heart failure } \\
\hline \multirow[t]{2}{*}{ Precardiotomy crash and burn } & $\begin{array}{l}\text { Refractory cardiogenic shock requiring emergent salvage operation: CPR en route to the } \\
\text { operating theatre or prior to anaesthesia induction }\end{array}$ \\
\hline & $\begin{array}{l}\text { Refractory cardiogenic shock (STS definition SBP }<80 \mathrm{mmHg} \text { and/or } \mathrm{Cl}<1.8 \mathrm{~L} / \text { minute } / \mathrm{m}^{2} \\
\text { despite maximal treatment) requiring emergency operation due to ongoing, refractory (difficult, } \\
\text { complicated, and/or unmanageable) unrelenting cardiac compromise resulting in life threatening } \\
\text { haemodynamic compromise }\end{array}$ \\
\hline Precardiotomy deteriorating fast & $\begin{array}{l}\text { Deteriorating haemodynamic instability: increasing doses of intravenous inotropes and/or IABP } \\
\text { necessary to maintain } \mathrm{SBP}>80 \mathrm{mmHg} \text { and/or } \mathrm{Cl}>1.8 \mathrm{~L} / \text { minute/m². Progressive deterioration. } \\
\text { Emergency operation required due to ongoing, refractory (difficult, complicated, and/or } \\
\text { unmanageable) unrelenting cardiac compromise, resulting in severe haemodynamic compromise }\end{array}$ \\
\hline Precardiotomy stable on inotropes & $\begin{array}{l}\text { Inotrope dependency: intravenous inotropes and/or IABP are necessary to maintain SBP } \\
>80 \mathrm{mmHg} \text { and/or } \mathrm{CI}>1.8 \mathrm{~L} / \text { minute/ } \mathrm{m}^{2} \text { without clinical improvement. Failure to wean from } \\
\text { inotropes (decreasing inotropes results in symptomatic hypotension or organ dysfunction). } \\
\text { Urgent operation is required }\end{array}$ \\
\hline
\end{tabular}

Failure to wean from $\mathrm{CPB}$

Failure to wean from CPB

Deteriorating fast on withdrawal from $C P B$

Stable but inotrope dependent on withdrawal from CPB

Postcardiotomy cardiogenic shock

Postcardiotomy crash and burn

Postcardiotomy deteriorating fast

Postcardiotomy stable on inotropes
Cardiac arrest after prolonged weaning time (>1 hour)

Deteriorating haemodynamic instability on withdrawal of CBP after prolonged weaning time (>1 hour)

Increasing doses of intravenous inotropes and/or IABP necessary to maintain SBP $>80 \mathrm{mmHg}$ and/or $\mathrm{Cl}>1.8 \mathrm{~L} /$ minute $/ \mathrm{m}^{2}$

Inotrope dependency on withdrawal of CBP after weaning time $>30$ minutes. Intravenous inotropes and/or IABP are necessary to maintain SBP $>80 \mathrm{mmHg}$ and/or $\mathrm{Cl}>1.8 \mathrm{~L} /$ minute $/ \mathrm{m}^{2}$ without clinical improvement

The high incidence of complications after VAD implantation is directly related to prolonged attempted weaning periods from CPB. Application of IABP within 30 minutes from the first attempt to wean from CPB and mechanical circulatory support within 1 hour from the first attempts to wean from the CPB are suggested [90]

\section{Cardiac arrest requiring CPR until intervention}

Refractory cardiogenic shock (SBP $<80 \mathrm{mmHg}$ and/or $\mathrm{Cl}<1.8 \mathrm{~L} /$ minute/m², critical organ hypoperfusion with systemic acidosis and/or increasing lactate levels despite maximal treatment, including inotropes and IABP) resulting in life threatening haemodynamic compromise. Emergency salvage intervention required

Deteriorating haemodynamic instability. Increasing doses of intravenous inotropes and/or IABP necessary to maintain $\mathrm{SBP}>80 \mathrm{mmHg}$ and/or $\mathrm{Cl}>1.8 \mathrm{~L} /$ minute $/ \mathrm{m}^{2}$. Progressive deterioration, worsening acidosis and increasing lactate levels. Emergent intervention required due to ongoing, refractory unrelenting cardiac compromise, resulting in severe haemodynamic compromise

Inotrope dependency: intravenous inotropes and/or IABP necessary to maintain SBP $>80 \mathrm{mmHg}$ and/or $\mathrm{Cl}>1.8 \mathrm{~L} /$ minute $/ \mathrm{m}^{2}$ without clinical improvement. Failure to decrease inotropic support

$\mathrm{Cl}$, cardiac index; $\mathrm{CPB}$, cardiopulmonary bypass; CPR, cardiopulmonary resuscitation; IABP, intra-aortic balloon pump; SBP, systolic blood pressure; STS, Society of Thoracic Surgeons; VAD, ventricular assist device.

\section{Failure to wean}

In the failure to wean from $\mathrm{CPB}$ profile, although the reason to perform surgery is more or less established, the basis for a successful therapeutic approach is establishing a correct diagnosis of cardiac failure as soon as possible. Acute HF associated with failure to wean patients off CPB may be surgery related, patient specific or both, as summarized in Table 3 [80]. Table 3 also lists the investigations necessary to ascertain the underlying cause of failure to wean from $\mathrm{CPB}$

\section{Postcardiotomy heart failure}

As patients with postcardiotomy HF are usually in the ICU, we can usually guesstimate the diagnosis. Sophisticated monitoring and diagnostic and therapeutic options are readily available should the need arise. Although the chest remains closed, it can be reopened quickly if needed, either in the ICU bed or in theatre following the patient's transfer back there. Support with cardiac assist devices can also be initiated, although not as promptly as in the failure to wean scenario. The 
priority is preserving end organ function and bridging the patient to recovery.

The initial strategy for management of postcardiotomy cardiac dysfunction includes the optimization of both preload appropriate to LV function and rhythm and support with positive inotropic and/or vasopressor agents and IABP. This strategy will restore haemodynamics in most patients. Requirements for optimal LV function and preservation of RV coronary perfusion include careful assessment of right-left ventricular interactions, ventricular-aorta coupling and adequate mean arterial pressure. [81]

When in postcardiotomy HF an IABP becomes necessary, survival rates between $40 \%$ and $60 \%$ have been reported. In more severe cases of postcardiotomy HF, reported rates of hospital discharge have been disappointing (6\% to $44 \%$ ) even with the implementation of extracorporeal ventricular assist devices [82].

A perioperative clinical severity classification of severe acute HF is suggested in Table 4.

\section{Mechanical circulatory support}

Group recommendations

- In case of heart dysfunction with suspected coronary hypoperfusion, IABP is highly recommended

- Ventricular assist device should be considered early rather than later, before end organ dysfunction is evident

- Extra-corporeal membrane oxygenation is an elegant solution as a bridge to recovery or decision making

\section{Intra-aortic balloon pump}

IABP is the first choice device in intra- and perioperative cardiac dysfunction. Its advantages include easy insertion (Seldinger technique), the modest increase in $\mathrm{CO}$ and coronary perfusion, and four decades of refined technology and experience resulting in a low complication rate. The IABP's main mechanism of action is a reduction of afterload and increased diastolic coronary perfusion via electrocardiogram triggered counterpulsation. However, the newer generations of IABPs are driven by aorta flow detection, thereby overcoming limitations in patients with atrial fibrillation and other arrhythmias. IABP reduces heart work and myocardial oxygen consumption, favourably modifying the balance of oxygen demand/supply.

Consequently, it is an ideal application in postcardiotomy cardiac dysfunction, especially in suspected coronary hypoperfusion. IABP insertion should be considered as soon as evidence points to possible cardiac dysfunction, preferably intraoperatively to avoid the excessive need of inotropic support.

IABP is contraindicated for patients with severe aortic insufficiency, and advanced peripheral and aortic vascular disease.

\section{Catheter based axial flow devices}

Experiences with the first miniaturized 14 Fr catheter based axial flow pump, used in the early 1980s (Hemopump), provided flow rates in the range of 2.0 to $2.5 \mathrm{~L} /$ minute, but initial mechanical problems limited its clinical application in supporting the failing heart.

A new design (Impella pump) provides a more stable mechanical function through modifications and improvements, including both the pump-head and the miniaturized motor mounted on the tip of the catheter. However, even with these improvements transfemoral placement is only possible with the smallest version of this pump; larger diameter versions require surgical placement. Pump versions are available for both LV and RV support. Increased flow rates in the range of 2.5 to $5.0 \mathrm{~L} /$ minute can be achieved directly in proportion with increasing diameter of the pumps. It is CE-marked for temporary use of 5 to 10 days only, and seems efficient in medium flow demands in postcardiotomy low $\mathrm{CO}$ syndrome.

\section{Extra-corporeal membrane oxygenation}

Extra-corporeal membrane oxygenation (ECMO) is increasingly used for temporary mechanical circulatory support due to the relatively low cost of the system and disposables, as well as its broad availability (practically accessible to all cardiosurgical units, without requiring a major investment in hardware). Indications include all types of ventricular failure, for example, intraoperative or perioperative low $\mathrm{CO}$ syndrome, severe acute myocardial infarction, and cardiac resuscitation. An additional advantage is its versatile use not only in LV, RV or biventricular support, but also for respiratory assistance and even renal support by addition of a haemofilter.

ECMO is a simplified CPB using a centrifugal pump (5 to $6 \mathrm{~L} /$ minute), allowing for augmentation of venous drainage despite relatively small cannulas, with the option of taking the full workload over from the heart. ECMO is not only used as a bridge to recovery, a bridge to transplantation, or a bridge to assist with middle and long-term assist devices, but also as a bridge to decision making - for example, neurological assessment after resuscitation prior to long-term assist/transplantation.

The limitations of ECMO mainly stem from the necessity of permanent operator supervision and intervention. Currently, many different ECMO configurations are available for temporary use up to 30 days. Although patients supported by ECMO can be extubated, they are usually bed-ridden and have to stay in the ICU, which is very much in contrast to modern ventricular assist device therapy (see below).

\section{Ventricular assist device}

Mechanical blood pumps, capable of taking over the full $\mathrm{CO}$ of the failing heart, are used today as an established 
therapy option for patients with end-stage HF. In the majority of cases only the failing LV needs mechanical support; pumps are therefore left ventricular assist devices. Patients with pronounced biventricular failure or patients in cardiogenic shock will nowadays receive biventricular mechanical support.

Besides achieving adequate perfusion of the peripheral organs, thereby facilitating survival in the ICU, increasingly the objective of modern ventricular assist device therapy is to obtain a level of functionality that results in an acceptable quality of life for the patient. Hence, weaning from the ventilator, mobilisation, transfer from the ICU to the general ward, excursions, discharge home, and ultimately return to work must be the goals when transplantation is not feasible within a reasonable time frame.

In terms of technology, the available pumps provide either pulsatile or continuous flow (may be modulated by residual ventricular function). In continuous flow, axial and centrifugal designs are distinguished. Almost all currently available second-generation rotary axial and centrifugal pumps require a transcutaneous drive line or cable, a serious limitation for the patient as well as a port of entry for infections. However, they can easily be miniaturized, produce no noise, have thin and flexible drive-lines and their driving units can be miniaturized to the size of a cigarette package. In third-generation rotary pumps the spinning rotor floats by means of either a magnetic field or hydrodynamic levitation, never touching the pump housing, thereby eliminating mechanical wear. The second and third generation pumps have prospective lifetimes of more than 10 years, producing an acceptable quality of life.

Steadily increasing implant numbers have improved clinical outcomes, with 1- and 2-year survival rates of approximately $90 \%$ and $80 \%$, respectively $[83,84]$.

In summary, in this day and age mechanical circulatory support should be considered as a course of treatment and not as a last effort in patients with failing hearts, especially those with perioperative cardiac dysfunction inadequately responding to advanced inotropic treatment. Initially, most patients demonstrating perioperative low $\mathrm{CO}$ syndrome receive short-term mechanical support. Under this initial support they stabilize or recover and can be weaned from the pump (bridge to recovery). Patients, whose cardiac function does not recover during the initial support and are eligible for cardiac transplantation can be switched to long-term mechanical support (bridge to transplantation, chronic mechanical support as an alternative to transplantation). If the haemodynamics are inadequate with an unclear indication for potentially long-term assist, ECMO provides an elegant low cost and short-term solution as a bridge to recovery. Table 5 summarizes short- and
Table 5. Mechanical circulatory support used in the three clinical heart failure scenarios

\begin{tabular}{ll}
\hline Clinical scenarios & Commonly used devices \\
\hline Precardiotomy HF & IABP \\
& Micro-axial flow pump \\
& Percutaneous (transfemoral) ECMO \\
& LA femoral artery centrifugal pump \\
& IABP \\
& Micro-axial flow pump \\
Failure to wean from CPB & ECMO \\
& Centrifugal pumps as LVAD, RVAD, \\
& BVAD \\
& Percutaneous pulsatile devices as \\
& LVAD, RVAD, BVAD \\
& Long-term implantable devices \\
& IABP \\
& Micro-axial flow pump \\
& ECMO \\
& Centrifugal pumps ${ }^{\mathrm{d}}$ as LVAD, RVAD, \\
& BVAD \\
Postcardiotomy HF & Percutaneous pulsatile devices ${ }^{\mathrm{c}}$ as \\
& LVAD, RVAD, BVAD \\
& Long-term implantable devices first, \\
& second and third generation \\
\hline
\end{tabular}

almpella; ${ }^{\mathrm{T}}$ TandemHeart; ${ }^{\mathrm{C}} \mathrm{Abiomed}$ BVS 5000, AB 5000; Thoratec PVAD, Berlin Heart EXCOR; ${ }^{\mathrm{d} C e n t r i m a g ~ L e v i t r o n i x, ~ B i o m e d i c u s ~ M e d t r o n i c ~ e t c . ~ I I ~ d e v i c e s ~ e x c e p t ~}$ those specified as long term are for short-term support. BVAD, bi-ventricular assist device; CPB, cardiopulmonary bypass; ECMO, extracorporeal membrane oxygenation; $\mathrm{HF}$, heart failure; IABP, intra-aortic balloon pump; $\mathrm{LA}$, left atrial; LVAD, left ventricular assist device; PVAD, paracorporeal ventricular assist device; RVAD, right ventricular assist device.

long-term mechanical circulatory devices used in the three clinical scenarios.

\section{Conclusion}

This review offers practical recommendations for managing perioperative HF in cardiac surgery based mostly on European experts' opinion. It outlines typical scenarios and profiles classifying and defining low $\mathrm{CO}$ syndrome and cardiogenic shock in cardiac surgery. As the role of inotropes is accentuated, the cardiosurgical community needs to have evidence-based facts on the short- and long-term mortality in cardiac surgery in European cardiosurgical centres. The impact of inotropes is increasingly studied outside of cardiac surgery, highlighting the urgent necessity for cardiac surgery to mimic these studies. Similarly, large trials are still required to assess the best cardioprotective agent(s) and optimal protocol(s) for their use. The continuously expanding implementation of mechanical circulatory support - by means of short-term (extra- or paracorporeal) and long-term (implantable) devices - demand its documentation and study in a European registry. 


\section{Competing interests}

All coauthors received reimbursement of travel expenses and/or a fee to participate at the workshop, entitled 'Management of Perioperative Cardiovascular Failure in Cardiothoracic Surgery' that was held in Zurich the 7th-8th of November 2008 for which event an Educational grant was received from Abbott. Dr Follath has received lecture fees and advisory board honoraria from Abbott. Dr Longrois reported being a consultant for Abbott and Orion Pharma. Dr Mebazaa reported being a consultant for Abbott, Orion Pharma, Pronota, Inverness and Bayer Pharma and receiving lecture fees from Abbott and Edwards Life Sciences. Dr Ranucci received consultancy fees from Edwards Lifesciences in the years 2006-2008 for Educational programs in the field of Hemodynamic monitoring; Edwards Lifesciences is not sponsoring this article. Dr Toller has received speaker's fees and advisory board fees from Abbott. Dr Wouters has received speaker's fees from Abbott for lectures on topics unrelated to this manuscript. Dr Seeberger is the principal investigator of the ongoing investigator initiated study: "The TEAM-project: multi-center trial on the effect of anesthetics on morbidity and mortality in patients undergoing major non cardiac surgery" that has received partial research funding by Abbott.

\section{Acknowledgements}

This initiative was sponsored by way of an educational grant from Abbott. The views expressed in this supplement are not necessarily the views of the sponsor.

\section{Author details}

'Department of Anaesthesia and Intensive care, INSERM UMR 942, Lariboisière Hospital, University of Paris 7 - Diderot, 2 rue Ambroise Paré, 75010 Paris, France. ${ }^{2}$ Thessaloniki Heart Institute, St Luke's Hospital, Thessaloniki, Greece, 552 36. Intensive Care Unit, Department of Internal Medicine, University Hospital Zurich, Raemistrasse 100, CH 8091 Zurich, Switzerland. Department of Anaesthesiology and Intensive Care Medicine, Medical University Graz, 8036 Graz, Austria. ${ }^{5}$ APHP, Hôpital Bichat-Claude Bernard, Département d'Anesthésie-Réanimation, University Paris 7 Denis Diderot, Unité INSERM U 698, Paris, France. ${ }^{6}$ Department of Cardiothoracic Anesthesia and Intensive Care, Sahlgrenska University Hospital, S-413 45 Gothenburg, Sweden. ${ }^{7}$ Department of Nephrology Dialysis and Transplantation, San Bortolo Hospital, Viale Rodolfi 37, 36100 Vicenza, Italy. ${ }^{8}$ Department of Anaesthesiology, Academic Medical Center, University of Amsterdam, 1105 Amsterdam, Netherlands. ${ }^{9}$ Department for Cardiothoracic Surgery, Medical University of Vienna, Waehringer Guertel 18-20, A-1090 Vienna, Austria. ${ }^{10}$ Institute of Anaesthesiology Heart and Diabetes-Center, Nordrhein-Westfalen University Clinic of Ruhr-University Bochum, Georgstrasse 11, D-32545 Bad Oeynhausen, Germany. "Department of Cardio-Vascular Surgery, CHUV, Rue du Bugnon 46, 1011 Lausanne, Switzerland. ${ }^{12}$ Department of Anaesthesiology and Intensive Care Medicine, Charité-Universitätsmedizin Berlin, Campus Charité Mitte and Campus Virchow-Klinikum, 10098 Berlin, Germany. ${ }^{13}$ Department of Vascular Surgery, Erasmus Medical Centre,'s Gravendijkwal 230, 3015 CE Rotterdam, the Netherlands. ${ }^{14}$ Department of Cardiothoracic and Vascular Anesthesia and ICU, IRCCS Policlinico S Donato, 20097 Milan, Italy. ${ }^{15}$ Department of Anesthesia, Chelsea and Westminster Hospital, 369 Fulham Road, London SW10 9NH, UK. ${ }^{16}$ Department of Anesthesia, University Hospital Ghent, De Pintelaan 185, B-9000 Ghent, ER Schmid Institute of Anaesthesiology, Division of Cardiovascular Anaesthesia, University Hospital Zurich, Raemistrasse 100, $\mathrm{CH}-8091$ Zurich, Switzerland. ${ }^{17}$ Department of Anesthesia, University Hospital, University of Basel, 4031 Basel, Switzerland. ${ }^{18}$ Institute of Anaesthesiology, Division of Cardiovascular Anaesthesia, University Hospital Zurich, Raemistrasse 100, CH-8091 Zurich, Switzerland. ${ }^{19}$ Division of Thoracic surgery, University Hospital Zurich, Raemistrasse 100, CH-8091 Zurich, Switzerland. 20University Hospital Zürich, CH 8091 Zürich, Rämistr. 100, Switzerland.

\section{Published: 28 April 2010}

\section{References}

1. Nieminen MS, Böhm M, Cowie MR, Drexler H, Filippatos GS, Jondeau G, Hasin Y, Lopez-Sendon J, Mebazaa A, Metra M, Rhodes A, Swedberg K, Priori SG, Garcia MA, Blanc JJ, Budaj A, Cowie MR, Dean V, Deckers J, Burgos EF, Lekakis J, Lindahl B, Mazzotta G, Morais J, Oto A, Smiseth OA, Garcia MA, Dickstein K, Albuquerque $A$, Conthe $P$, et al.: Executive summary of the guidelines on the diagnosis and treatment of acute heart failure: the Task Force on Acute Heart Failure of the European Society of Cardiology. Eur Heart J 2005,
26:384-416

2. Rudiger A, Harjola VP, Muller A, Mattila E, Saila P, Nieminen M, Follath F: Acute heart failure: clinical presentation, one-year mortality and prognostic factors. Eur J Heart Fail 2005, 7:662-670.

3. Siirila-Waris K, Lassus J, Melin J, Peuhkurinen K, Nieminen MS, Harjola VP: Characteristics, outcomes, and predictors of 1-year mortality in patients hospitalized for acute heart failure. Eur Heart J 2006, 27:301 1-3017.

4. Tavazzi L, Maggioni AP, Lucci D, Cacciatore G, Ansalone G, Oliva F, Porcu M: Nationwide survey on acute heart failure in cardiology ward services in Italy. Eur Heart J 2006, 27:1207-1215.

5. Nieminen MS, Brutsaert D, Dickstein $K$, Drexler $H$, Follath F, Harjola VP, Hochadel M, Komajda M, Lassus J, Lopez-Sendon JL, Ponikowski P, Tavazzi L; EuroHeart Survey Investigators; Heart Failure Association, European Society of Cardiology: EuroHeart Failure Survey II (EHFS II): a survey on hospitalized acute heart failure patients: description of population. Eur Heart J 2006, 27:2725-2736

6. Zannad F, Mebazaa A, Juillière Y, Cohen-Solal A, Guize L, Alla F, Rougé P, Blin P Barlet MH, Paolozzi L, Vincent C, Desnos M, Samii K; EFICA Investigators: Clinical profile, contemporary management and one-year mortality in patients with severe acute heart failure syndromes: The EFICA study. Eur J Heart Fail 2006, 8:697-705.

7. Fleisher LA, Beckman JA, Brown KA, Calkins H, Chaikof E, Fleischmann KE, Freeman WK, Froehlich JB, Kasper EK, Kersten JR, Riegel B, Robb JF; ACC/AHA TASK FORCE MEMBERS, Smith SC Jr, Jacobs AK, Adams CD, Anderson JL, Antman EM, Buller CE, Creager MA, Ettinger SM, Faxon DP, Fuster V, Halperin $J$, Hiratzka LF, Hunt SA, Lytle BW, Md RN, Ornato JP, Page RL, et al:: ACC/AHA 2007 Guidelines on Perioperative Cardiovascular Evaluation and Care for Noncardiac Surgery: Executive Summary: A Report of the American College of Cardiology/American Heart Association Task Force on Practice Guidelines (Writing Committee to Revise the 2002 Guidelines on Perioperative Cardiovascular Evaluation for Noncardiac Surgery): Developed in Collaboration With the American Society of Echocardiography, American Society of Nuclear Cardiology, Heart Rhythm Society, Society of Cardiovascular Anesthesiologists, Society for Cardiovascular Angiography and Interventions, Society for Vascular Medicine and Biology, and Society for Vascular Surgery. Circulation 2007, 116:1971-1996.

8. Task Force for Diagnosis and Treatment of Acute and Chronic Heart Failure 2008 of European Society of Cardiology, Dickstein K, Cohen-Solal A, Filippatos G, McMurray JJ, Ponikowski P, Poole-Wilson PA, Strömberg A, van Veldhuisen DJ, Atar D, Hoes AW, Keren A, Mebazaa A, Nieminen M, Priori SG, Swedberg K; ESC Committee for Practice Guidelines, Vahanian A, Camm J, De Caterina R, Dean V, Dickstein K, Filippatos G, Funck-Brentano C, Hellemans I, Kristensen SD, McGregor K, Sechtem U, Silber S, Tendera M, et al:: ESC Guidelines for the diagnosis and treatment of acute and chronic heart failure 2008: the Task Force for the Diagnosis and Treatment of Acute and Chronic Heart Failure 2008 of the European Society of Cardiology. Developed in collaboration with the Heart Failure Association of the ESC (HFA) and endorsed by the European Society of Intensive Care Medicine (ESICM). Eur Heart J 2008, 29:2388-2442.

9. Jessup M, Abraham WT, Casey DE, Feldman AM, Francis GS, Ganiats TG, Konstam MA, Mancini DM, Rahko PS, Silver MA, Stevenson LW, Yancy CW: 2009 focused update: ACCF/AHA Guidelines for the Diagnosis and Management of Heart Failure in Adults: a report of the American College of Cardiology Foundation/American Heart Association Task Force on Practice Guidelines: developed in collaboration with the International Society for Heart and Lung Transplantation. Circulation 2009, 119:1977-2016.

10. Rudiger A, Businger F, Streit M, Schmid ER, Maggiorini M, Follath F: Presentation and outcome of critically ill medical and cardiac-surgery patients with acute heart failure. Swiss Med Wkly 2009, 139:1 10-116.

11. Pae WE Jr, Miller CA, Matthews Y, Pierce WS: Ventricular assist devices for postcardiotomy cardiogenic shock. A combined registry experience. J Thorac Cardiovasc Surg 1992, 104:541-552; discussion 552-553.

12. Tritapepe L, De Santis V, Vitale D, Guarracino F, Pellegrini F, Pietropaoli P, Singer M: Levosimendan pre-treatment improves outcomes in patients undergoing coronary artery bypass graft surgery. Br J Anaesth 2009, 102:198-204.

13. Davila-Roman VG, Waggoner AD, Hopkins WE, Barzilai B: Right ventricular dysfunction in low output syndrome after cardiac operations: assessment by transesophageal echocardiography. Ann Thorac Surg 1995, 60:1081-1086. 
14. Dunser MW, Mayr AJ, Ulmer H, Ritsch N, Knotzer H, Pajk W, Luckner G, Mutz NJ, Hasibeder WR: The effects of vasopressin on systemic hemodynamics in catecholamine-resistant septic and postcardiotomy shock: a retrospective analysis. Anesth Analg 2001, 93:7-13.

15. Morales DL, Garrido MJ, Madigan JD, Helman DN, Faber J, Williams MR, Landry DW, Oz MC: A double-blind randomized trial: prophylactic vasopressin reduces hypotension after cardiopulmonary bypass. Ann Thorac Surg 2003, 75:926-930

16. Nashef SA, Roques F, Michel P, Gauducheau E, Lemeshow S, Salamon R: European system for cardiac operative risk evaluation (EuroSCORE). Eur J Cardiothorac Surg 1999, 16:9-13.

17. Rao V, Ivanov J, Weisel RD, Ikonomidis JS, Christakis GT, David TE: Predictors of low cardiac output syndrome after coronary artery bypass. J Thorac Cardiovasc Surg 1996, 112:38-51

18. Kazmers A, Cerqueira MD, Zierler RE: Perioperative and late outcome in patients with left ventricular ejection fraction of $35 \%$ or less who require major vascular surgery. J Vasc Surg 1988, 8:307-315.

19. Bhatti F, Grayson AD, Grotte G, Fabri BM, Au J, Jones M, Bridgewater B: The logistic EuroSCORE in cardiac surgery: how well does it predict operative risk? Heart 2006, 92:1817-1820.

20. Matsuura K, Ogino H, Matsuda H, Minatoya K, Sasaki H, Yagihara T, Kitamura S: Limitations of EuroSCORE for measurement of risk-stratified mortality in aortic arch surgery using selective cerebral perfusion: is advanced age no longer a risk? Ann Thorac Surg 2006, 81:2084-2087.

21. Grossi EA, Schwartz CF, Yu PJ, Jorde UP, Crooke GA, Grau JB, Ribakove GH, Baumann FG, Ursumanno P, Culliford AT, Colvin SB, Galloway AC: High-risk aortic valve replacement: are the outcomes as bad as predicted? Ann Thorac Surg 2008, 85:102-106; discussion 107

22. Choong CK, Sergeant P, Nashef SA, Smith JA, Bridgewater B: The EuroSCORE risk stratification system in the current era: how accurate is it and what should be done if it is inaccurate? Eur J Cardiothorac Surg 2009, 35:59-61.

23. Zheng Z, Li Y, Zhang S, Hu S: The Chinese coronary artery bypass grafting registry study: how well does the EuroSCORE predict operative risk for Chinese population? Eur J Cardiothorac Surg 2009, 35:54-58.

24. D'Errigo P, Seccareccia F, Rosato S, Manno V, Badoni G, Fusco D, Perucci CA Comparison between an empirically derived model and the EuroSCORE system in the evaluation of hospital performance: the example of the Italian CABG Outcome Project. Eur J Cardiothorac Surg 2008, 33:325-333.

25. Maisel A, Mueller C, Adams K Jr, Anker SD, Aspromonte N, Cleland JG, CohenSolal A, Dahlstrom U, DeMaria A, Di Somma S, Filippatos GS, Fonarow GC, Jourdain P, Komajda M, Liu PP, McDonagh T, McDonald K, Mebazaa A, Nieminen MS, Peacock WF, Tubaro M, Valle R, Vanderhyden M, Yancy CW, Zannad F, Braunwald E: State of the art: using natriuretic peptide levels in clinical practice. Eur J Heart Fail 2008, 10:824-839.

26. Jankowski M: B-type natriuretic peptide for diagnosis and therapy. Recent Pat Cardiovasc Drug Discov 2008, 3:77-83

27. Hutfless R, Kazanegra R, Madani M, Bhalla MA, Tulua-Tata A, Chen A, Clopton $P$, James C, Chiu A, Maisel AS: Utility of B-type natriuretic peptide in predicting postoperative complications and outcomes in patients undergoing heart surgery. J Am Coll Cardiol 2004, 43:1873-1879.

28. Pedrazzini GB, Masson S, Latini R, Klersy C, Rossi MG, Pasotti E, Faletra FF, Siclari F, Minervini F, Moccetti T, Auricchio A: Comparison of brain natriuretic peptide plasma levels versus logistic EuroSCORE in predicting in-hospital and late postoperative mortality in patients undergoing aortic valve replacement for symptomatic aortic stenosis. Am J Cardio/ 2008, 102:749-754.

29. Eliasdottir SB, Klemenzson G, Torfason B, Valsson F: Brain natriuretic peptide is a good predictor for outcome in cardiac surgery. Acta Anaesthesio/ Scand 2008, 52:182-187.

30. Ross S, Foex P: Protective effects of anaesthetics in reversible and irreversible ischaemia-reperfusion injury. Br J Anaesth 1999, 82:622-632.

31. De Hert SG, Turani F, Mathur S, Stowe DF: Cardioprotection with volatile anesthetics: mechanisms and clinical implications. Anesth Analg 2005, 100:1584-1593.

32. Bein $B$, Turowski $P$, Renner J, Hanss R, Steinfath $M$, Scholz J, Tonner PH: Comparison of xenon-based anaesthesia compared with total intravenous anaesthesia in high risk surgical patients. Anaesthesia 2005, 60:960-967.

33. Conzen PF, Fischer S, Detter C, Peter K: Sevoflurane provides greater protection of the myocardium than propofol in patients undergoing off-pump coronary artery bypass surgery. Anesthesiology 2003, 99:826-833.

34. De Hert SG, Cromheecke S, ten Broecke PW, Mertens E, De Blier IG, Stockman BA, Rodrigus IE, Van der Linden PJ: Effects of propofol, desflurane, and sevoflurane on recovery of myocardial function after coronary surgery in elderly high-risk patients. Anesthesiology 2003, 99:314-323.

35. De Hert SG, ten Broecke PW, Mertens E, Van Sommeren EW, De Blier IG, Stockman BA, Rodrigus IE: Sevoflurane but not propofol preserves myocardial function in coronary surgery patients. Anesthesiology 2002, 97:42-49.

36. De Hert SG, Van der Linden PJ, Cromheecke S, Meeus R, Nelis A, Van Reeth V, ten Broecke PW, De Blier IG, Stockman BA, Rodrigus IE: Cardioprotective properties of sevoflurane in patients undergoing coronary surgery with cardiopulmonary bypass are related to the modalities of its administration. Anesthesiology 2004, 101:299-310.

37. Landoni G, Biondi-Zoccai GG, Zangrillo A, Bignami E, D'Avolio S, Marchetti C, Calabrò MG, Fochi O, Guarracino F, Tritapepe L, De Hert S, Torri G: Desflurane and sevoflurane in cardiac surgery: a meta-analysis of randomized clinical trials. J Cardiothorac Vasc Anesth 2007, 21:502-511.

38. Jakobsen CJ, Berg H, Hindsholm KB, Faddy N, Sloth E: The influence of propofol versus sevoflurane anesthesia on outcome in 10,535 cardiac surgical procedures. J Cardiothorac Vasc Anesth 2007, 21:664-671.

39. Du Toit EF, Muller CA, McCarthy J, Opie LH: Levosimendan: effects of a calcium sensitizer on function and arrhythmias and cyclic nucleotide levels during ischemia/reperfusion in the Langendorff-perfused guinea pig heart. J Pharmacol Exp Ther 1999, 290:505-514

40. Sonntag S, Sundberg S, Lehtonen LA, Kleber FX: The calcium sensitizer levosimendan improves the function of stunned myocardium after percutaneous transluminal coronary angioplasty in acute myocardial ischemia. J Am Coll Cardiol 2004, 43:2177-2182.

41. Zangrillo A, Biondi-Zoccai G, Mizzi A, Bruno G, Bignami E, Gerli C, De Santis V, Tritapepe L, Landoni G: Levosimendan reduces cardiac troponin release after cardiac surgery: a meta-analysis of randomized controlled studies. $J$ Cardiothorac Vasc Anesth 2009, 23:474-478.

42. De Hert SG, Lorsomradee S, vanden Eede H, Cromheecke S, Van der Linden PJ: A randomized trial evaluating different modalities of levosimendan administration in cardiac surgery patients with myocardial dysfunction. J Cardiothorac Vasc Anesth 2008, 22:699-705.

43. Soeding PE, Royse CF, Wright CE, Royse AG, Angus JA: Inoprotection: the perioperative role of levosimendan. Anaesth Intensive Care 2007, 35:845-862.

44. Buhre W, Weyland A, Schorn B, Scholz M, Kazmaier S, Hoeft A, Sonntag H: Changes in central venous pressure and pulmonary capillary wedge pressure do not indicate changes in right and left heart volume in patients undergoing coronary artery bypass surgery. Eur J Anaesthesiol 1999, 16:11-17.

45. Godje O, Peyerl M, Seebauer T, Lamm P, Mair H, Reichart B: Central venous pressure, pulmonary capillary wedge pressure and intrathoracic blood volumes as preload indicators in cardiac surgery patients. Eur J Cardiothorac Surg 1998, 13:533-539; discussion 539-540.

46. Kumar A, Anel R, Bunnell E, Habet K, Zanotti S, Marshall S, Neumann A, Ali A, Cheang M, Kavinsky C, Parrillo JE: Pulmonary artery occlusion pressure and central venous pressure fail to predict ventricular filling volume, cardiac performance, or the response to volume infusion in normal subjects. Crit Care Med 2004, 32:691-699.

47. Shippy CR, Appel PL, Shoemaker WC: Reliability of clinical monitoring to assess blood volume in critically ill patients. Crit Care Med 1984, 12:107-112.

48. Buhre W, Buhre K, Kazmaier S, Sonntag H, Weyland A: Assessment of cardiac preload by indicator dilution and transoesophageal echocardiography. Eur J Anaesthesio/ 2001, 18:662-667.

49. Lichtwarck-Aschoff M, Beale R, Pfeiffer UJ: Central venous pressure, pulmonary artery occlusion pressure, intrathoracic blood volume, and right ventricular end-diastolic volume as indicators of cardiac preload. $J$ Crit Care 1996, 11:180-188.

50. Wiesenack C, Prasser C, Keyl C, Rodig G: Assessment of intrathoracic blood volume as an indicator of cardiac preload: single transpulmonary thermodilution technique versus assessment of pressure preload parameters derived from a pulmonary artery catheter. $J$ Cardiothorac Vasc Anesth 2001, 15:584-588.

51. Cavallaro F, Sandroni C, Antonelli M: Functional hemodynamic monitoring and dynamic indices of fluid responsiveness. Minerva Anestesio/ 2008 , 74:123-135.

52. Sander M, Spies CD, Berger K, Grubitzsch H, Foer A, Kramer M, Carl M, von Heymann C: Prediction of volume response under open-chest conditions during coronary artery bypass surgery. Crit Care 2007, 11:R121.

53. Couture P, Denault AY, McKenty S, Boudreault D, Plante F, Perron R, Babin D, 
Normandin L, Poirier N: Impact of routine use of intraoperative transesophageal echocardiography during cardiac surgery. Can J Anaesth 2000, 47:20-26.

54. Mebazaa A, Karpati P, Renaud E, Algotsson L: Acute right ventricular failure from pathophysiology to new treatments. Intensive Care Med 2004, 30:185-196.

55. Fellahi JL, Parienti JJ, Hanouz JL, Plaud B, Riou B, Ouattara A: Perioperative use of dobutamine in cardiac surgery and adverse cardiac outcome: propensity-adjusted analyses. Anesthesiology 2008, 108:979-987.

56. Gillies M, Bellomo R, Doolan L, Buxton B: Bench-to-bedside review: Inotropic drug therapy after adult cardiac surgery - a systematic literature review. Crit Care 2005, 9:266-279.

57. Butterworth JFt, Prielipp RC, Royster RL, Spray BJ, Kon ND, Wallenhaupt SL, Zaloga GP: Dobutamine increases heart rate more than epinephrine in patients recovering from aortocoronary bypass surgery. J Cardiothorac Vasc Anesth 1992, 6:535-541.

58. Fowler MB, Alderman EL, Oesterle SN, Derby G, Daughters GT, Stinson EB, Ingels NB, Mitchell RS, Miller DC: Dobutamine and dopamine after cardiac surgery: greater augmentation of myocardial blood flow with dobutamine. Circulation 1984, 70:1103-111.

59. Gunnicker M, Brinkmann M, Donovan TJ, Freund U, Schieffer M, Reidemeister $J C$ : The efficacy of amrinone or adrenaline on low cardiac output following cardiopulmonary bypass in patients with coronary artery disease undergoing preoperative beta-blockade. Thorac Cardiovasc Surg 1995 43:153-160

60. Svedjeholm R, Hallhagen S, Ekroth R, Joachimsson PO, Ronquist G: Dopamine and high-dose insulin infusion (glucose-insulin-potassium) after a cardiac operation: effects on myocardial metabolism. Ann Thorac Surg 1991, 51:262-270.

61. Rosseel PM, Santman FW, Bouter H, Dott CS: Postcardiac surgery low cardiac output syndrome: dopexamine or dopamine? Intensive Care Med 1997, 23:962-968.

62. MacGregor DA, Butterworth JFt, Zaloga CP, Prielipp RC, James R, Royster RL: Hemodynamic and renal effects of dopexamine and dobutamine in patients with reduced cardiac output following coronary artery bypass grafting. Chest 1994, 106:835-841.

63. Kikura M, Sato S: The efficacy of preemptive Milrinone or Amrinone therapy in patients undergoing coronary artery bypass grafting. Anesth Analg 2002, 94:22-30

64. Rathmell JP, Prielipp RC, Butterworth JF, Williams E, Villamaria F, Testa L, Viscomi C, Ittleman FP, Baisden CE, Royster RL: A multicenter, randomized, blind comparison of amrinone with milrinone after elective cardiac surgery. Anesth Analg 1998, 86:683-690.

65. Zerkowski HR, Gunnicker M, Freund U, Dieterich HA, Dressler HT, Doetsch N, Schieffer M, Hakim-Meibodi K, Lockhart JD, Reidemeister JC: Low-output syndrome after heart surgery: is a monotherapy with phosphodiesteraseIII inhibitors feasible? A comparative study of amrinone and enoximone. Thorac Cardiovasc Surg 1992, 40:371-377.

66. Dupuis JY, Bondy R, Cattran C, Nathan HJ, Wynands JE: Amrinone and dobutamine as primary treatment of low cardiac output syndrome following coronary artery surgery: a comparison of their effects on hemodynamics and outcome. J Cardiothorac Vasc Anesth 1992, 6:542-553.

67. Feneck RO, Sherry KM, Withington PS, Oduro-Dominah A: Comparison of the hemodynamic effects of milrinone with dobutamine in patients after cardiac surgery. J Cardiothorac Vasc Anesth 2001, 15:306-315.

68. Tarr TJ, Moore NA, Frazer RS, Shearer ES, Desmond MJ: Haemodynamic effects and comparison of enoximone, dobutamine and dopamine following mitral valve surgery. Eur J Anaesthesiol Supp/ 1993, 8:15-24.

69. Al-Shawaf E, Ayed A, Vislocky I, Radomir B, Dehrab N, Tarazi R: Levosimendan or milrinone in the type 2 diabetic patient with low ejection fraction undergoing elective coronary artery surgery. $J$ Cardiothorac Vasc Anesth 2006, 20:353-357.

70. Labriola C, Siro-Brigiani M, Carrata F, Santangelo E, Amantea B: Hemodynamic effects of levosimendan in patients with low-output heart failure after cardiac surgery. Int I Clin Pharmacol Ther 2004, 42:204-211.

71. Siirila-Waris K, Suojaranta-Ylinen R, Harjola VP: Levosimendan in cardiac surgery. J Cardiothorac Vasc Anesth 2005, 19:345-349.

72. Alvarez J, Bouzada M, Fernandez AL, Caruezo V, Taboada M, Rodriguez J, Ginesta V, Rubio J, Garcia-Bengoechea JB, Gonzalez-Juanatey JR: [Hemodynamic effects of levosimendan compared with dobutamine in patients with low cardiac output after cardiac surgery]. Rev Esp Cardiol
2006, 59:338-345

73. Levin RL, Degrange MA, Porcile R, Salvagio F, Blanco N, Botbol AL, Tanus E, del Mazo CD: [The calcium sensitizer levosimendan gives superior results to dobutamine in postoperative low cardiac output syndrome]. Rev Esp Cardiol 2008, 61:471-479.

74. De Hert SG, Lorsomradee S, Cromheecke S, Van der Linden PJ: The effects of levosimendan in cardiac surgery patients with poor left ventricular function. Anesth Analg 2007, 104:766-773.

75. Michaels AD, McKeown B, Kostal M, Vakharia KT, Jordan MV, Gerber IL, Foster $E$, Chatterjee K: Effects of intravenous levosimendan on human coronary vasomotor regulation, left ventricular wall stress, and myocardial oxygen uptake. Circulation 2005, 111:1504-1509.

76. Jorgensen K, Bech-Hanssen O, Houltz E, Ricksten SE: Effects of levosimendan on left ventricular relaxation and early filling at maintained preload and afterload conditions after aortic valve replacement for aortic stenosis. Circulation 2008, 117:1075-1081

77. Yau TM, Ikonomidis JS, Weisel RD, Mickle DA, Ivanov J, Mohabeer MK, Tumiat $\mathrm{L}$, Carson S, Liu P: Ventricular function after normothermic versus hypothermic cardioplegia. J Thorac Cardiovasc Surg 1993, 105:833-843; discussion 843-844

78. Teoh KH, Christakis GT, Weisel RD, Fremes SE, Mickle DA, Romaschin AD, Harding RS, Ivanov J, Madonik MM, Ross IM, et al:: Accelerated myocardial metabolic recovery with terminal warm blood cardioplegia. JThorac Cardiovasc Surg 1986, 91:888-895.

79. Christakis GT, Weisel RD, Fremes SE, Ivanov J, David TE, Goldman BS, Salerno TA: Coronary artery bypass grafting in patients with poor ventricular function. Cardiovascular Surgeons of the University of Toronto. J Thorac Cardiovasc Surg 1992, 103:1083-1091; discussion 1091-1092.

80. Fedoruk LM, Kron IL: An unusual case of cardiac dysfunction after left ventricular reconstruction. J Cardiothorac Surg 2006, 1:28.

81. Cotter G, Moshkovitz Y, Kaluski E, Milo O, Nobikov Y, Schneeweiss A, Krakover $R$, Vered $Z$ : The role of cardiac power and systemic vascular resistance in the pathophysiology and diagnosis of patients with acute congestive heart failure. Eur J Heart Fail 2003, 5:443-451.

82. Helman DN, Morales DL, Edwards NM, Mancini DM, Chen JM, Rose EA, Oz MC: Left ventricular assist device bridge-to-transplant network improves survival after failed cardiotomy. Ann Thorac Surg 1999, 68:1187-1194.

83. Miller LW, Pagani FD, Russell SD, John R, Boyle AJ, Aaronson KD, Conte JV Naka Y, Mancini D, Delgado RM, MacGillivray TE, Farrar DJ, Frazier OH; HeartMate II Clinical Investigators: Use of a continuous-flow device in patients awaiting heart transplantation. N Eng/ J Med 2007, 357:885-896.

84. Wieselthaler G, O'Driscoll G, Jansz P, Khaghani A, Strueber M: First clinical experience with the novel HeartWare HVAD pump with hydrodynamically levitated rotor in a multiinstitutional trial. J Heart Lung Transp/2009, in press.

85. Pons JM, Granados A, Espinas JA, Borras JM, Martin I, Moreno V: Assessing open heart surgery mortality in Catalonia (Spain) through a predictive risk model. Eur J Cardiothorac Surg 1997, 11:415-423.

86. Roques F, Gabrielle F, Michel P, De Vincentiis C, David M, Baudet E: Quality of care in adult heart surgery: proposal for a self-assessment approach based on a French multicenter study. Eur J Cardiothorac Surg 1995, 9:433-439.

87. Tu JV, Jaglal SB, Naylor CD: Multicenter validation of a risk index for mortality, intensive care unit stay, and overall hospital length of stay after cardiac surgery. Steering Committee of the Provincial Adult Cardiac Care Network of Ontario. Circulation 1995, 91:677-684

88. Higgins TL, Estafanous FG, Loop FD, Beck GJ, Blum JM, Paranandi L: Stratification of morbidity and mortality outcome by preoperative risk factors in coronary artery bypass patients. A clinical severity score. JAMA 1992, 267:2344-2348

89. Parsonnet $V$, Dean $D$, Bernstein AD: A method of uniform stratification of risk for evaluating the results of surgery in acquired adult heart disease. Circulation 1989, 79:13-12.

90. Samuels LE, Kaufman MS, Thomas MP, Holmes EC, Brockman SK, Wechsler AS: Pharmacological criteria for ventricular assist device insertion following postcardiotomy shock: experience with the Abiomed BVS system. J Card Surg 1999, 14:288-293.

doi:10.1186/cc8153

Cite this article as: Mebazaa A et al. Practical recommendations on the management of perioperative heart failure in cardiac surgery. Critical Care 2010, 14:201. 